\title{
HUBUNGAN SANITASI DENGAN INFEKSI TELUR CACING PADA ANAK SEKOLAH DASAR
}

\author{
Sri Idayani, Ni Luh Nova Dilisca Dwi Putri, I Putu Oka Dharmawan \\ Sekolah Tinggi Ilmu Kesehatan Wira Medika Bali \\ Jl. Kecak No. 9A Gatot Subroto Timur, Denpasar-Bali 80239, Telp./Fax. (0361) 427699 \\ Email: iid_wika@yahoo.com
}

\begin{abstract}
Worm infections in humans are caused by intestinal nematode worms, namely Soil Transmitted Helminths (STH), which are transmitted through contaminated soil through direct contact with parasite eggs or larvae in the soil. School-age children are a group that has a high risk of STH infection because they are often exposed to soil, contaminated water, and lack of awareness of personal hygiene. Soil Transmitted Helminth (STH) transmission through eggs is excreted in the form of feces or urine which contaminates soil and water that has poor sanitation and water supply. Worm infection in children of basic age can cause stunted growth and development of children, disability, and blindness. The purpose of this study was to determine the relationship between environmental sanitation and infection of intestinal worm eggs (Soil Transmitted Helmint) in elementary school children in Bangli Regency. Respondents who were examined were 30, namely elementary school students in Bangli Regency starting from grades 1-6. School environmental sanitation data obtained by a questionnaire with the observation method. The data on worms for the respondents were obtained by taking fecal samples and examined using the direct method at the Parasitology Laboratory of STIKes Wira Medika Bali. The results showed that the overall sanitation condition of the school environment in Bangli Regency was 90\% good and the prevalence of worm infections in elementary school children in Bangli Regency was $3.3 \%$. There is no relationship between environmental sanitation and infection of intestinal worm eggs (Soil Transmitted Helmint) in elementary school children in Bangli Regency (p-value > 0.05)..
\end{abstract}

Keywords: Soil Transmitted Helmints, elementary school children, direct slide method, Necator americanus

\section{PENDAHULUAN}

Penyakit parasit usus salah satunya disebabkan oleh cacing usus, infeksi cacing pada manusia salah satunya disebabkan oleh cacing nematoda usus yaitu Soil Transmitted Helminths (STH). Penularannya melalui tanah yang terkontaminasi melalui kontak langsung dengan telur parasit atau larva yang berada di tanah. Spesies Soil Transmitted Helminth (STH) yang menginfeksi manusia yaitu Ascaris lumbricoides, Trichuris trichiura, Necator americanus, Ancylostoma duodenale, dan Strongyloides stercoralis (Faizul, 2012).

Anak usia sekolah merupakan kelompok yang mempunyai resiko tinggi terinfeksi Soil Transmitted Helminth (STH), karena sering terpapar dengan tanah dan air yang terkontaminasi, kurangnya kesadaran higienitas diri yang baik. Transmisi Soil Transmitted Helminth (STH) melalui telur yang diekskresikan melalui feses atau urin yang mengkontaminasi tanah dan air yang memiliki sanitasi tidak baik dan persediaan air yang tidak memadai dan aman (WHO, 2011)

Infeksi kecacingan dapat disebabkan oleh beberapa faktor. Salah satu faktor yang menyebabkan kecacingan yaitu sanitasi lingkungan. Hal tersebut meliputi sanitasi sumber air, pembuangan kotoran manusia, dan sanitasi makanan yang mendukung ke arah 
infeksi cacingan. Sedangkan faktor sanitasi makanan yang mendukung ke arah kejadian infeksi cacingan yaitu perilaku makan dalam kehidupan sehari-hari, misalnya mengkonsumsi makanan secara mentah atau setengah matang berupa ikan, daging dan sayuran serta penyajian makanan harus bebas dari kontaminasi (Andaruni, dkk., 2012). Menurut penelitian Amirawati (2012), masih tingginya angka kesakitan penyakit menular di Indonesia seperti cacingan antara lain dipengaruhi oleh tidak tersedianya air bersih, tidak adanya sarana pembuangan air limbah, dan kurangnya kebersihan lingkungan perumahan.

Beberapa penelitian mengenai infeksi cacing pada anak Sekolah Dasar didapatkan prevalensi kejadian infeksi kecacingan sebanyak 40,21\% karena faktor jenis lantai, ketersediaan air bersih, kepemilikan tempat sampah, dan sarana pembuangan air limbah di SD Barengan Kecamatan Teras Kabupaten Boyolali (Umi, 2017). Penelitian lain yang dilakukan Kusumawardani, et.al tahun 2019 menunjukkan adanya hubungan yang signifikan antara kejadian infeksi Soil Transmitted Helminth (STH) dengan sarana pembuangan tinja tetapi tidak terdapat hubungan antara kejadian infeksi STH dengan sanitasi lingkungan, jenis kelamin, usia, sumber air bersih, saluran pembuangan air limbah (SPAL), sarana pembuangan sampah dan jenis lantai rumah. Prevalensi infeksi cacing STH pada anak Sekolah dasar di Gianyar Bali adalah $16 \%$ dengan prevalensi tertinggi pada jenis cacing Trichiuris trichiura (13\%) karena dipengaruhi faktor kebiasaan tidak mencuci tangan dengan sabun, kuku tangan yang kotor dan tidak memiliki jamban (Subrata, 2016).

Berdasarkan data dari Dinas

Kesehatan Provinsi Bali tahun 2017 menyebutkan bahwa prevalensi kecacingan di Bali masih dalam kelompok sedang yang masuk di kisaran 20-40\%, tepatnya $24 \%$ (Wahyuni, dkk., 2018). Menurut penelitian Pratiwi dkk (2018) menunjukkan bahwa prevalensi kecacingan di SDN 1 Blandingan Kabupaten Bangli, Bali dari 273 anak sekolah dasar yang positif kecacingan adalah sebanyak 17 orang $(6,2 \%)$ dan anak yang negatif kecacingan sebanyak 256 orang (93,8\%), dengan mayoritas responden adalah berumur 8 tahun.

Tujuan penelitian ini adalah untuk mengetahui hubungan antara infeksi cacing usus (Soil Transmitted Helmint) dengan sanitasi lingkungan pada anak Sekolah Dasar Negeri X di Banjar Yeh Panas Desa Songan Kecamatan Kintamani Kabupaten Bangli.

\section{METODE}

Penelitian ini merupakan penelitian deskriptif korelatif dengan pendekatan cross sectional. Sampel yang diperiksa fesesnya adalah sebanyak 30 responden yang terdiri dari anak sekolah dasar dari kelas 1-6 dari total 293 keseluruhan anak Sekolah Dasar Negeri X di Banjar Yeh Panas Desa Songan Kecamatan Kintamani Kabupaten Bangli. 
Cara pengambilan sampel dilakukan secara purposive sampling, kriteria responden yang diambil adalah anak yang bisa berkomunikasi dengan baik dan tidak minum obat cacing selama 6 bulan terakhir. Sampel feses diperiksa infeksi telur cacingnya Data sanitasi lingkungan responden diperoleh dengan wawancara dan observasi sekolah. Penelitian akan dilanjutkan dengan pemeriksaan kejadian kecacingan pada feses anak Sekolah Dasar di Bangli dengan metode langsung (direct method) di Laboratorium Parasitologi STIKes Wira Medika Bali untuk mengetahui jenis telur cacing yang menginfeksi responden.

Untuk melakukan analisis secara keseluruhan tentang kondisi sanitasi lingkungan, maka dilakukan skoring untuk menilai aspek-aspek lingkungan tersebut. Dari hasil skoring tersebut diperoleh rerata skor kondisi sanitasi lingkungan sekolah adalah 5 dengan skor terendah 0 dan tertinggi 5 . Dengan menggunakan batasan kondisi sanitasi lingkungan "baik" apabila skor $\geq 5$ dan kondisi sanitasi lingkungan "buruk" apabila skor $<5$, maka diperoleh gambaran distribusi kondisi sanitasi lingkungan seperti pada Tabel 1 diatas. Hasil penelitian dianalisa menggunakan uji Korelasi Spearman kemudian interpretasikan secara deskriptif.

\section{HASIL DAN PEMBAHASAN}

Pernyataan responden terhadap sanitasi lingkungan sekolah dan hasil pemeriksaan sampel terlihat dari pernyataan responden terhadap indikator sanitasi lingkungan sekolah dan hasil pemeriksaan sampel tersebut. Pernyataan dan hasil pemeriksaan responden seperti terlihat pada Tabel 1.

Tabel 1. Distribusi Frekuensi Responden Berdasarkan Sanitasi Lingkungan Sekolah

\begin{tabular}{ccc}
\hline Sanitasi Lingkungan & Frekuensi & Prosentase \\
\hline Baik & 27 & 90 \\
Buruk & 3 & 10 \\
\hline Jumlah & 30 & 100
\end{tabular}

Sumber: Hasil Penelitian 2020 (Data diolah)

Tabel 1 menunjukkan bahwa sebagian besar responden yaitu sebanyak 27 orang (90\%) menyatakan bahwa kondisi sanitasi lingkungan sekolah baik. Selanjutnya 3 orang
(10\%) responden menyatakan bahwa kondisi sanitasi lingkungan sekolah buruk berdasarkan hasil wawancara dan observasi. 
Idayani, S., dkk: Hubungan Sanitasi dengan Infeksi Telur Cacing pada Anak Sekolah Dasar

Tabel 2. Distribusi Frekuensi Responden Berdasarkan Pemeriksaan Terhadap Sampel Feses

\begin{tabular}{ccc}
\hline Pemeriksaan Feses & Frekuensi & Prosentase \\
\hline $\begin{array}{c}\text { (-) Ascaris lumbricoides, Trichuris } \\
\text { trichiura, Ancylostoma duodenale } \\
\text { (+) Necator americanus }\end{array}$ & 29 & 96,7 \\
\hline Jumlah & 1 & 3,3 \\
\hline
\end{tabular}

Sumber: Hasil Penelitian 2020 (Data diolah)

Tabel 2 menunjukkan bahwa sebagian besar responden yaitu sebanyak 29 orang $(96,7 \%)$ tidak terinfeksi telur cacing Soil Transmitted orang $(3,3 \%)$ terinfeksi telur cacing Soil Transmitted Helminth (STH) dari jenis spesies Necator americanus.

Helminth (STH). Selanjutnya sebanyak 1

Tabel 3. Hubungan Sanitasi Lingkungan dengan Infeksi Telur Cacing Usus (Soil Transmitted Helminths) pada Anak Sekolah Dasar Negeri X di Banjar Yeh Panas Desa Songan Kecamatan Kintamani Kabupaten Bangli

\begin{tabular}{|c|c|c|c|c|c|c|c|}
\hline \multirow{3}{*}{$\begin{array}{c}\text { Sanitasi } \\
\text { Lingkungan }\end{array}$} & \multicolumn{4}{|c|}{ Kejadian Kecacingan } & \multirow{2}{*}{\multicolumn{2}{|c|}{ Total }} & \multirow{3}{*}{ Sig. $p$} \\
\hline & \multicolumn{2}{|c|}{ Positif } & \multicolumn{2}{|c|}{ Negatif } & & & \\
\hline & $\mathbf{N}$ & $\%$ & $\mathbf{N}$ & $\%$ & $\mathbf{N}$ & $\%$ & \\
\hline Baik & 1 & 3,7 & 26 & 96,3 & 27 & 100 & 1,00 \\
\hline Buruk & 0 & 0 & 3 & 100 & 3 & 100 & \\
\hline Jumlah & 1 & & 29 & & 30 & 100 & \\
\hline
\end{tabular}

Sumber: Hasil Penelitian 2020 (Data diolah)

Tabel 3 menunjukkan bahwa tidak terdapat hubungan antara sanitasi lingkungan dengan kejadian infeksi kecacingan telur cacing Soil Transmitted Helminth $(\mathrm{STH})(\mathrm{p}=1,00)$.

Jenis telur cacing yang diperiksa adalah Soil Transmitted Helminths (STH). Soil Transmitted Helminths (STH) merupakan nematoda usus yang ditularkan lewat tanah serta juga ditularkan melalui kotoran hewan yang menyebabkan infeksi cacing (Salim, 2013). Nematoda usus yang penularannya melalui tanah disebut jenis Soil Transmitted Helminths (STH) (WHO, 2016). Jenis Soil Transmitted Helminth (STH) yang paling banyak menyebabkan infeksi cacingan, seperti cacing gelang (Ascaris lumbricoides), cacing cambuk (Trichuris trichiura), cacing tambang
(Necator americanus dan Ancylostoma duodenale) dan Strongyloides stercolaris (Samuel et al., 2017). Cacing dewasa yang hidup di usus manusia mampu menghasikan ribuan telur setiap hari. Hal ini menyebabkan telur dapat mengkontaminasi tanah pada area dengan sanitasi yang kurang baik. Soil Transmitted Helminths (STH) dapat masuk ketubuh manusia dengan berbagai cara, yaitu dari anak-anak yang bermain tanah yang telah terkontaminasi Soil Transmitted Helminths (STH), sayuran yang tidak dicuci bersih yang terkontaminasi telur cacing, anak-anak yang sering bermain tidak menggunakan alas kaki, tidak mencuci tangan sebelum makan, memiliki kuku tangan yang panjang dan tidak 
Idayani, S., dkk: Hubungan Sanitasi dengan Infeksi Telur Cacing pada Anak Sekolah Dasar

memperhatikan kebersihan perorangan (WHO,2014).

Berdasarkan Tabel 2 hasil pemeriksaan sampel feses secara laboratorium ditemukan 1 responden yang positif terinfeksi telur cacing Soil Transmitted Helminths (STH). Jenis cacing Soil Transmitted Helminth yang ditemukan adalah dari spesies Necator americanus.

Necator americanus merupakan salah satu cacing tambang yang paling banyak menginfeksi masyarakat Indonesia (Pusarawati, 2014). Cacing ini hidup dalam usus halus. Pada infeksi berat, cacing dapat tersebar sampai ke kolon dan duodenum. Telur cacing tambang berdinding tipis dan tembus cahaya ini mengandung embrio dengan empat blastomer (Soedarto, 2016).

Hasil pemeriksaan telur cacing Soil Transmitted Helminths (STH) pada anak sekolah dasar diperoleh sabanyak 29 responden tidak terinfeksi telur cacing spesies Soil Transmitted Helminths (STH). Infeksi kecacingan lebih banyak terjadi pada kondisi sanitasi lingkungan yang buruk. Menurut WHO (2013) penyakit cacing berhubungan dengan keberadaan cacing tambang pada tanah halaman rumah, sanitasi buruk, kebiasaan bermain lama di tanah dan kebiasaan defekasi di kebun (WHO, 2013).

Gambaran kondisi sanitasi lingkungan di tempat penelitian adalah secara keseluruhan sudah baik. Kondisi halaman sekolah bersih. Sumber air di sekolah dari sumur tertutup. Tempat cuci tangan ada dan bersih. Toilet di sekolah bersih dan tidak ada genangan air.
Kondisi jamban tertutup dan tidak bau. Kondisi lantai sekolah sudah berlantai dari semen. Tersedia tempat pembuangan sampah dan saluran pembuangan air limbah.

Hasil uji Korelasi Spearman menunjukkan tidak adanya korelasi antara variabel sanitasi lingkungan dengan infeksi telur cacing usus (Soil Transmitted Helminth) pada anak sekolah dasar di Kabupaten Bangli (nilai $-p>0,05$ ). Bila dilihat dari masing- masing aspek lingkungan yang lebih spesifik sebagai indikator lingkungan untuk terjadinya infeksi kecacingan adalah kondisi lantai sekolah ternyata hasilnya sama. Hasil ini kemungkinan disebabkan oleh faktor perilaku yang lebih dominan untuk terjadinya suatu infeksi dan kemungkinan terjadinya infeksi berasal dari luar sekolah seperti di rumah ataupun tempat lain biasa anak bermain.

Infeksi cacing pada manusia dapat dipengaruhi oleh perilaku, lingkungan tempat tinggal dan manipulasinya terhadap lingkungan (Wintoko, 2014). Infeksi cacing pada anak usia dasar berdampak buruk terhadap perkembangan kesehatan dan mental bahkan dapat menghambat tumbuh kembang anak, kecacatan, dan kebutaan (Sri, 2016). Anak dengan infeksi kecacingan ringan biasanya tidak menimbulkan gejala, akan tetapi infeksi berat dapat menimbulkan manifestasi usus seperti diare dan sakit perut, serta mengalami kondisi lemas pada badan akibat terus membuang air besar serta terganggunya perkembangan fisik dan anemia (WHO, 2013). 


\section{KESIMPULAN DAN SARAN}

\section{Kesimpulan}

Kesimpulan dari penelitian ini adalah kondisi sanitasi lingkungan sekolah di Sekolah Dasar Negeri Bangli baik (90\%). Angka infeksi kecacingan pada anak Sekolah Dasar Negeri X di Banjar Yeh Panas Desa Songan Kecamatan Kintamani Kabupaten Bangli adalah 3,3\% terinfeksi telur cacing usus (Soil Transmitted Helmint), spesies Necator americanus. Tidak terdapat hubungan yang bermakna antara sanitasi lingkungan dengan infeksi cacing usus (Soil Transmitted Helminth) pada anak Sekolah Dasar di Kabupaten Bangli. Perlu dilakukan penelitian lanjutan dengan jumlah sampel yang lebih banyak sehingga diperoleh hasil yang lebih maksimal.

\section{DAFTAR PUSTAKA}

Amirawati, S., "Gambaran Hygiene Peorangan, Sanitasi Lingkungan Sekolah, Dan Infeksi Kecacingan Pada Murid SD Inpres Cambaya Sungguminasa Gowa". Skripsi: Fakultas Ilmu Kesehatan Arc. Com. Health. 3(2) : 30-38, 2012.

Andaruni, A., Fatimah, S., Simangunsong, B., "Gambaran Faktor-faktor Penyebab Infeksi Cacingan Pada Anak Di SDN 01 Pasirkangu Cisaura," Skripsi. Bandung. Universitas Padjajaran, 2012.

Faizul, F., "Perbandingan Hasil Pemeriksaan Telur Soil Transmitted Helminth pada Tanah dengan Metode Flotasi $\mathrm{NaCl}$ Jenuh (Willis) dan Metode Suzuki," (KTI), Semarang, 2012.

Kartini, S., Kejadian Kecacingan pada siswa Sekolah Dasar Negeri Kecamatan Rumbai Pesisir Pekanbaru. Jurnal Komunitas: Vol 3, No.2, 2016.

Kusumawardani, N. A., Sulistyaningsih, E., \& Komariah, C. (2019). Hubungan sanitasi lingkungan dengan kejadian infeksi Soil Transmitted Helminths pada anak Sekolah Dasar di Jember. e-Journal Pustaka Kesehatan. 7(1), 45-51.

Mahmudah, U., "Hubungan Sanitasi Lingkungan Rumah Terhadap Kejadian Infeksi Kecacingan Pada Anak Sekolah Dasar," Jurnal Kesehatan. 10 (1) : 32-39, 2017.

Pratiwi, I.A.I.L., Swastika, I.K., Sudarmaja, I.M, "Pengaruh Infeksi Soil Transmitted Helminth (STH) terhadap Daya Ingat dan Koordinasi Visual-Motorik dalam Fungsi Kognitif Anak-Anak SDN 1 Sulangai, Kabupaten Badung, dan SDN 1 Blandingan, Kabupaten Bangli, Bali,” EJurnal Medika Udayana 7(4):148-154, 2018.

Pusarawati, "Atlas Parasitologi Kedokteran," Jakarta: Kedokteran EGC, 2014.

Salim, M., "Faktor-faktor yang Berhubungan dengan Positif Telur Cacing Soil Transmitted Helminths (STH) pada Petani Pengguna Pupuk Kandang di Desa Rasau Jaya Umum Tahun 2013," Pontianak, 2013.

Samuel, F., A. Demsew, Y. Alem, dan Y. Hailesilassie., "Soil Transmitted Helminthiasis and Associated Risk Factors Among Elementary School Children In Ambo Town, Western Ethiopia," BMC Public Health., 17: 1-7, 2017.

Soedarto, "Buku Ajar Parasitologi Kedokteran Edisi kedua," Jakarta : CV Sagung Seto, 2016.

Subrata, I Made, dan Nuryanti, "Pengaruh Personal Higiene Dan Sanitasi Lingkungan Terhadap Infeksi Soil Transmitted Helminths Pada Anak Sekolah Dasar Di Kabupaten Gianyar", 2016.

Wahyuni, D., Kurniawati, Y., "Prevalensi Kecacingan dan Kasus Gizi Pada Anak Sekolah Dasar Di Wilayah Kerja Puskesmas Nusa Penida (NP) III, 
Idayani, S., dkk: Hubungan Sanitasi dengan Infeksi Telur Cacing pada Anak Sekolah Dasar

Klungkung Bali," Jurnal Ilmiah

Kesehatan. 10 (2), pp : 2301-9255, 2018.

WHO., "Soil Transmitted Helminth Infection," fact sheet NO 366 Upload June 2013 (Online) http://www.who.int diakses tanggal 12 November 2019, 2013.

Wintoko, R., "Hubungan Aspek Personal Hygiene Dan Aspek Perilaku Dengan Kontaminasi Telur Cacing Pada Kuku Siswa Kelas 3, 4 Dan 5 Di Sdn 2 Rajabasa Kabupaten Bandar Lampung Tahun Ajaran 2012/2013," Juke Unila. 4(7): 136-41, 2014.

World Health Organization (WHO)." Working to overcome the global impact of neglected tropical disease" First WHO report on neglected tropical disease. Nonserial Publication. WHO, 2016.

World Health Organization, " Infeksi Soil Transmitted Helmith," 2014.

World Health Organization, "Helminth Control in School-Age Children: A Guide for Managers of Control Programs", http://whqlibdoc.who.int/2011. 